UNIVERSIDADE DE BRASÍLIA

FACULDADE DE CEILÂNDIA

PROGRAMA DE PÓS-GRADUAÇÃO EM CIÊNCIAS E TECNOLOGIAS EM SAÚDE MESTRADO

ELIENE MARTINS DE LIRA

EXERCÍCIO RESISTIDO REDUZ A ATIVIDADE DA MMP-2 NO TENDÃO DO QUADRÍCEPS E NO LIGAMENTO PATELAR DE RATOS INDUZIDOS A OSTEOARTRITE

BRASÍLIA

2017 


\section{ELIENE MARTINS DE LIRA}

\section{EXERCÍCIO RESISTIDO REDUZ A ATIVIDADE DA MMP-2 NO TENDÃO DO QUADRÍCEPS E NO LIGAMENTO PATELAR DE RATOS INDUZIDOS A OSTEOARTRITE}

Dissertação apresentada ao Programa de Pósgraduação em Ciências e Tecnologias em Saúde da Universidade de Brasília, como requisito parcial para obtenção do título de Mestre.

Orientadora: Prof. ${ }^{a}$ Dr. ${ }^{a}$ Rita de Cássia Marqueti Durigan

\section{BRASÍLIA}


ELIENE MARTINS DE LIRA

\section{EXERCÍCIO RESISTIDO REDUZ A ATIVIDADE DA MMP-2 NO TENDÃO DO QUADRÍCEPS E NO LIGAMENTO PATELAR DE RATOS INDUZIDOS A OSTEOARTRITE}

Dissertação apresentada ao Programa de Pósgraduação em Ciências e Tecnologias em Saúde da Universidade de Brasília, como requisito parcial para obtenção do título de Mestre.

Aprovado em__ de ___ de 2017.

BANCA EXAMINADORA

Prof. ${ }^{a}$ Dr. ${ }^{a}$ Rita de Cássia Marqueti Durigan

Universidade de Brasília

Orientadora

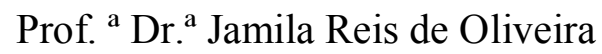

Universidade de Brasília

Prof. ${ }^{a}$ Dr. ${ }^{\text {a }}$ Elaine Cristina Leite Pereira

Universidade de Brasília 


\section{AGRADECIMENTOS}

A Deus, pelo amparo nos momentos difícies da minha vida, me dando muita força e vontade para seguir em frente. Sua bondade é sempre infinita e tem me mostrado da forma mais bonita possível.

A minha orientadora, a Prof. ${ }^{a}$ Dr. ${ }^{\text {a }}$ Rita Marquetti Durigan, agradeço de todo coração por cada ensinamento, cada gesto humano de me corrigir porque sem eles não teria conseguido finalizar essa etapa. Por mostrar que estamos nessa vida para aprender, para contribuir e por ser exemplo de profissional, acreditando em mim e ensinando o caminho da ciência de forma tão apaixonante. Obrigada professora por toda paciência. Sempre serei grata por tudo.

Ao Prof. Dr. João Luiz Quagliotti Durigan, por acreditar que poderia seguir com meu sonho logo após a graduação. Cada email entregue na fase inicial do processo era uma esperança plantada, uma alegria sem tamanho. Professor, muito obrigada. Nunca vou esquecer a forma como me acolheu no seu grupo de pesquisa.

À minha família. Aos meus pais que mesmo distante me apoiaram nos momentos mais

difíceis e sempre me ensinaram a não desistir dos meus sonhos. Às minhas irmãs, Ellene, Emeline e Eliza: vocês são meu amparo. Obrigada por aguentar cada estresse. Amo vocês.

Ao grupo de pesquisa GPlast, por cada conhecimento, cada amigo que conquistei, mostrando o significado de companheirismo, e pela força nas etapas durante esses dois anos.

Ao Conselho Nacional de Desenvolvimento Científico e Tecnológico (CNPq) pelo apoio financeiro de colaboração ao Programa de Mestrado da Universidade de Brasília. 


\section{RESUMO}

Objetivos: O objetivo do estudo foi avaliar a atividade da MMP-2 no tendão do músculo quadríceps e no ligamento patelar após treinamento resistido em modelo animal induzido à osteoartrite (OA) após lesão do ligamento cruzado anterior (LCA). Métodos: Foram utilizados 36 ratos (com peso 300 aproximado $\pm 10 \mathrm{~g}$ ) divididos em 6 grupos experimentais, $(\mathrm{n}=6 /$ cada): controle (C), osteoartrite (OA), sham (S), exercício (E), osteoartrite e exercício (OAE), sham e exercício (SE). O treinamento de força foi realizado durante oito semanas no qual os animais subiram uma escada vertical de $1,1 \mathrm{~m}$ com pesos conectados a suas caudas. Os animais realizaram 10 sessões com intervalo de 30 segundos entre cada subida, 3 vezes por semana, em dias alternados durante um período total de 8 semanas. A atividade da MMP-2 foi analisada por zimografia. Resultados: Houve diminuição significativa nas bandas pró, intermediária e ativada MMP-2 no grupo de osteoartrite exercício (OAE) quando comparada com os grupos osteoartrite (OA) e sham com exercício (SE) em ambos, tendão quadríceps e ligamento patelar ( $<<0,05)$. Além disso, quando comparado o conteúdo da MMP-2 entre os dois tecidos (tendão e ligamento), um maior conteúdo de MMP-2 foi observado no ligamento do que no tendão patelar $(\mathrm{p}<0,05)$. Conclusão: $O$ exercício resistido realizado durante oito semanas modulou positivamente a

atividade de MMP-2 no tendão quadríceps e no ligamento patelar com OA. Dessa forma, a regulação negativa da ativação de MMP-2 representa uma resposta positiva promovida pelo treinamento para o tendão quadríceps e ligamento patelar em animais com OA. Assim como, importância clínica, o treinamento resistido pode atuar na redução de expressão da MMP-2 em quadros de OA preservando a articulação e minimizando a progressão da doença.

Palavras-chave: Treinamento resistido. MMP-2. Tendão quadríceps. Ligamento patelar. Osteoartrite. 


\begin{abstract}
Aims: The aim of the study was to evaluate the MMP-2 activation in the tendon and patellar ligament after strength training exercise in rats model submitted toanterior cruciate ligamentinjury. Methods: We have evaluated 36 male rats (with an approximate weight $300 \pm 10 \mathrm{~g}$ ) divided into 6 experimental groups, $(n=6 /$ each) control $(\mathrm{C})$, osteoarthritis (OA), sham (S), exercise (E), osteoarthritis with exercise (OAE), sham with exercise (SE). An eight week strength training period, during which the animals climbed a $1.1-\mathrm{m}$ vertical ladder with weights attached to their tails. The animals performed 10 sessions climbingwith 30 seconds interval between each climb, 3 sessions per week on alternate days for a total period of 8 weeks. The MMP-2 activity was analyzed by zymography. Results: There wassignificant decreased in active-, intermediateand pro-MMP-2in the osteoarthritis with exercise (OE) group when compared to the osteoarthritis (OA) and sham with exercise (SE) group in both tendon and patellar ligament $(\mathrm{P}<$ 0.05). In addition, a novel finding was that active, intermediate and pro-MMP-2 activity differed between tissues and a higher activity in the patellar ligament when compared to patellar tendon was observed respectively $(\mathrm{P}<0.05)$. Conclusion: The strength exercise carried out for eight weeks changed the MMP-2 activity in the tendon and patellar ligament with injury. Thus, downregulation of MMP-2 activation seems be a positive response for the patellar tendon and patellar ligament in animals with OA subjected to strength exercise program. It is highly possible that strength training exercise intervention for osteoarthritis will target the decrease of MMP-2 expression.
\end{abstract}

Key words: Strength training. MMP-2. Patellar tendon. Patellar ligament. Osteoarthritis. 


\section{LISTA DE ABREVIATURAS E SIGLAS}

$\begin{array}{ll}\text { MEC } & \text { Matriz Extracelular } \\ \text { GAGs } & \text { Glicosamoniglicanos } \\ \text { MMPs } & \text { Metaloproteinases de Matriz } \\ \text { TIMPs } & \text { Inibidores Teciduais de Metaloproteinases } \\ \text { OA } & \text { Osteoartrite } \\ \text { LCA } & \text { Ligamento Cruzado Anterior } \\ \text { VEGF } & \text { Fator de Crescimento Endotelial Vascular } \\ \text { S } & \text { Sham } \\ \text { E } & \text { Exercício } \\ \text { C } & \text { Controle } \\ \text { OAE } & \text { Osteoartrite e Exercício } \\ \text { SE } & \text { Sham e Exercício }\end{array}$




\section{LISTA DE ILUSTRAÇÕES}

Figura 1. Vista anterior do joelho direito mostrando o tendão do quadríceps e o ligamento patelar.

Figura 2. Organização hierárquica do tendão. 10

Figura 3-A. Estágio inicial da osteoartrite. 14

Figura 3-B. Estágio tardio da osteoartrite. 15

Figura 4. Vista anterior do joelho. Ligamento cruzado anterior. 16

Figura 5. Protocolo de treinamento resistido. Escada vertical.

Gráfico 1. Conteúdo de MMP-2 das isoformas, pró, intermediária e ativa do tendão quadríceps após 8 semanas de exercício resistido.

Gráfico 2. Conteúdo de MMP-2 das isoformas, pró, intermediária e ativa do ligamento patelar após 8 semanas de exercício resistido.

Gráfico 3. Comparação entre o tendão quadríceps e o ligamento patelar após 8 semanas de $\begin{array}{lllll}\text { treinamento } & \text { resistido } & \text { nas } & \text { isoformas }\end{array}$ 2. 


\section{SUMÁRIO}

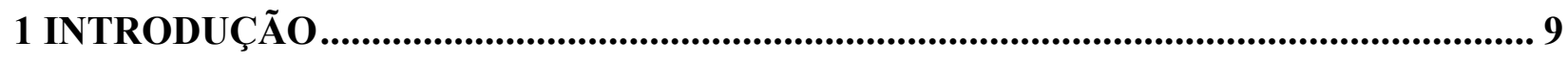

1.1 Morfologia tendínea e ligamentar........................................................................................... 9

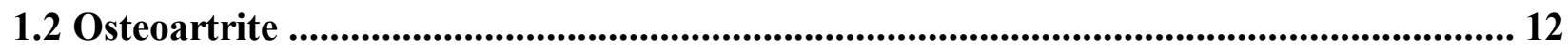

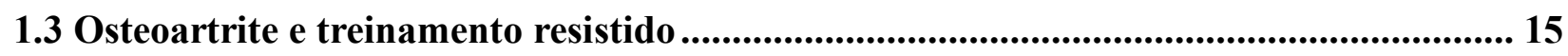

1.4 O papel das metaloproteinases de matriz na osteoartrite..................................................... 17

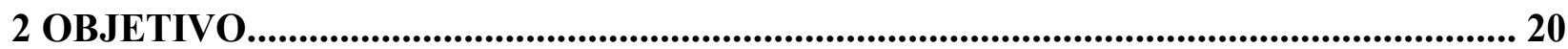

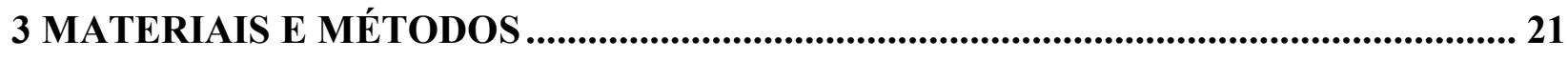

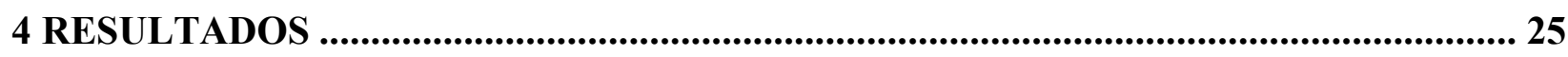

4.1 Tendão patelar ............................................................................................................... 25

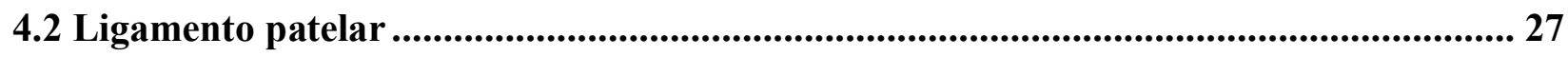

4.3 Tendão do quadríceps versus ligamento patelar................................................................. 29

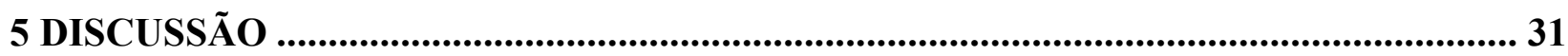

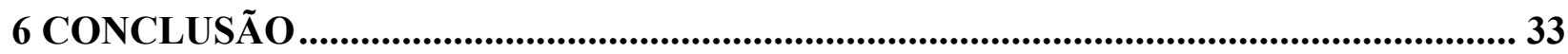

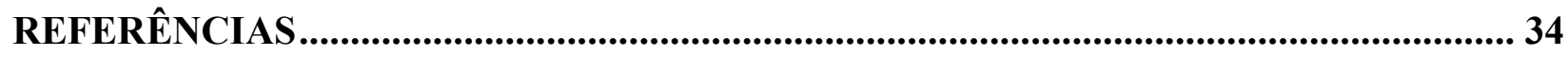




\section{INTRODUÇÃO}

\subsection{Morfologia tendínea e ligamentar}

Os componentes do músculo quadríceps femoral se inserem na patela como um tendão constituído por três camadas, sendo, portanto, uma estrutura trilaminar: o tendão do músculo reto femoral (superficialmente), o tendão do músculo vasto medial e lateral (camada intermediária) e o tendão do músculo vasto intermédio (camada profunda). Sua verdadeira inserção é na tuberosidade da tíbia, sendo o ligamento patelar conhecido como seu prolongamento (WALIGORA; JOHANSON; HIRSCH, 2009) (Figura 1).

O ligamento patelar se estende até a tuberosidade da tíbia e é definido como um feixe ligamentoso que se encontra entre o tecido subcutâneo e a bolsa pré-tibial ou infrapatelar profunda (BIANCHI et al., 1994; TORNIN, 2012).

Figura 1. Vista anterior do joelho direito mostrando o tendão do quadríceps e o ligamento patelar

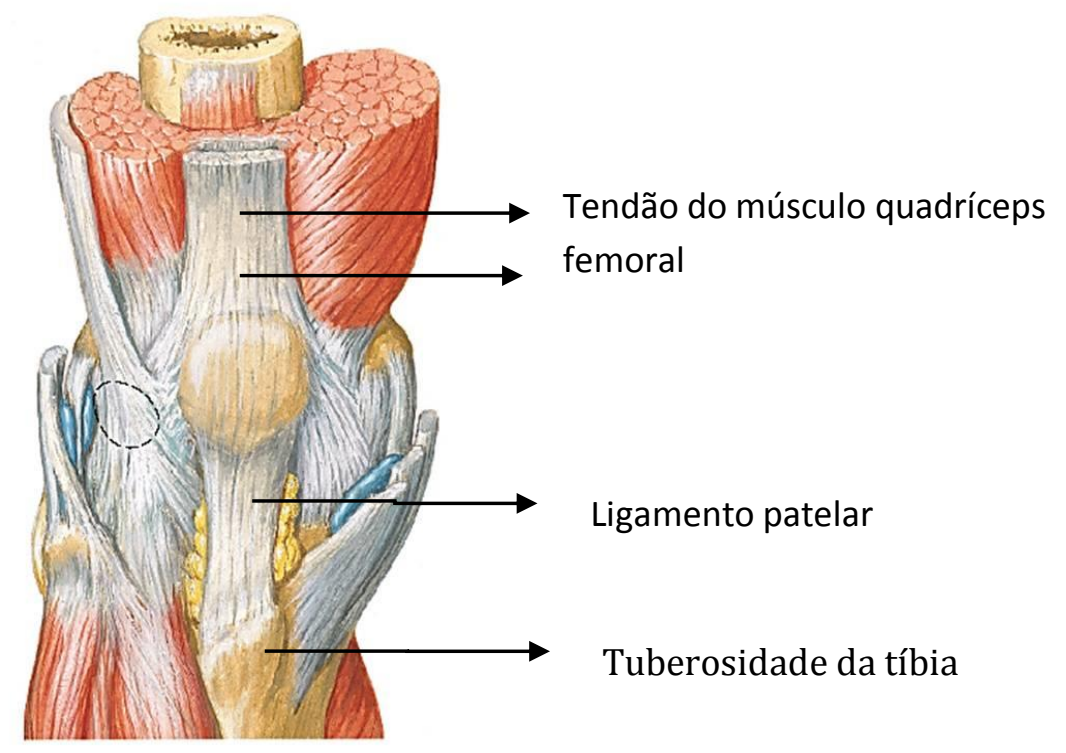

Fonte: NETTER (2015).

O tendão é um componente anatômico dos músculos estriados esqueléticos, composto por tecido conjuntivo denso (CONNIZZO; YANNASCOLI; SOSLOWSKY, 2013). É composto, 
predominante, por colágeno tipo I organizado hierarquicamente em fibrilas, fibras, feixes e fascículos que correm paralelamente ao longo do eixo de força do tendão de forma a resistir a altas forças de tração entre os músculos e ossos. Os feixes de fibras colágenas estão embutidos em proteínas da matriz extracelular (MEC), incluindo os proteoglicanos (FRIZZIERO et al., 2011). O colágeno tipo II, III e V e pequenas quantidades de tipos de colágeno XII e XIV, também estão presentes nos tendões, porém em menor quantidade (KOSTROMINOVA e BROOKS, 2013) (Figura 2).

Figura 2. Organização hierárquica do tendão

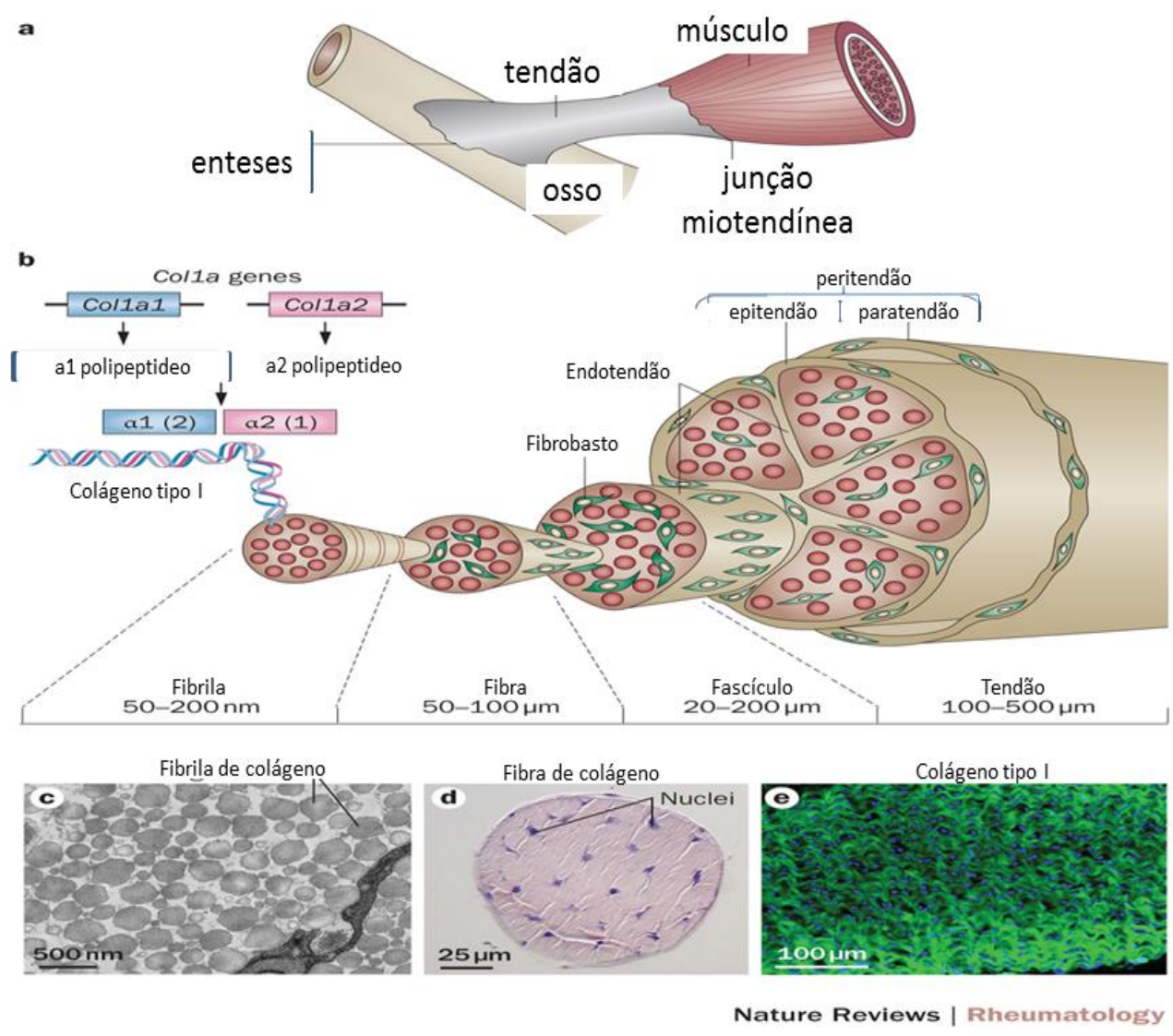

Fonte: NOURISSAT; BERENBAUM; DUPREZ (2015)

Ainda, entre as fibrilas de colágeno estão presentes células que são responsáveis pela síntese e manutenção da MEC com papel fundamental no metabolismo dos proteoglicanos, chamado de fibrócitos. São fibroblastos que apresentam morfologia alongada e, quando ocorre sua diferenciação e maturidade, são chamados de fibrócitos. O controle de diferenciação dos 
fibrócitos e suas células progenitoras parecem ser essencial ao desenvolvimento do tendão, reparação e seu remodelamento (MAGNE; BOUGAULT, 2015).

A população de células do tendão é heterogênea e mal definida, sem marcadores claros disponíveis para identificar as células. Pelo menos duas populações celulares distintas são evidentes no tendão: os fibroblastos, especializados altamente alongados dentro de fascículos (fibrócitos), que sintetizam uma MEC rica em colágeno, e uma população de células mais arredondadas na matriz interfascicular, que parecem ser metabolicamente mais ativas que os fibroblastos (SCREEN et al., 2015).

Os proteoglicanos são frequentemente associados com fibrilas de colágeno ou ácido hialurônico. Proteínas como a elastina, proteína de ligação, proteína da matriz da cartilagem oligomérica, tenascina-C, que modula a adesão celular e fibronectina também está presente na matriz extracelular do tendão e estão envolvidos na organização e sinalização da MEC (YOON; HALPER, 2005). Apesar de proteoglicanos compor em aproximadamente $1 \%$ do peso seco das regiões de tração dos tendões, eles contribuem para a biomecânica e propriedades estruturais da matriz extracelular do tendão (PARKINSON et al., 2011).

Os proteoglicanos encontrados no tendão são classificados em dois grupos: 1) os pequenos proteoglicanos ricos em leucina (SLRPs) em que a decorina é o principal, constituindo aproximadamente $90 \%$ do conteúdo total de proteoglicanos, encontrada predominantemente na região tensional do tendão (IOZZO e MURDOCH, 1996; YOON e HALPER, 2005). Também estão presentes a biglicana, a fibromodulina, a lumican e a Keratocana, este último com papel na regulação da matriz de colágeno (REES et al., 2008); e 2) os grandes proteoglicanos de agregação, são caracterizados pela presença de domínios globulares separados por ligações de glicosaminoglicanos (GAGs) da região (PARKINSON et al., 2011; MAGN e BOUGAULT, 2015).

Os ligamentos possuem estruturas semelhantes, com pouca variação na sua celularidade, atividade metabólica e vascularização, dependendo do tamanho, função e atividade metabólica. Assim como os tendões, também são compostos por feixes de colágeno (75\%) organizados ao longo do eixo de força, dois terços de água, elastina (4,5\%), glicosaminoglicanos $(0,5 \%)$, entre outras substancias (PECORA et al., 2001).

O sistema elástico dos ligamentos possui três tipos de fibras: fibras oxitalânicas, que são secretadas pelos fibroblastos e que irão formar a fibra elástica; fibras elaunínicas formadas pela 
aderência da substancia amorfa, elastina, as microfibrilas; e fibras elásticas maduras. Esse sistema compõe a elastogênese, responsável pela elasticidade e resistência oxitalônica do tecido (PECORA et al., 2001).

A sustentação e proteção dos tecidos do tendão e ligamento dependem da quantidade e organização da matriz extracelular (MEC), com seus componentes como o colágeno, fibronectina, a própria elastina bem como as metaloproteinases de matriz (MMPs) que participam da degradação do colágeno e de outras proteínas da MEC (MARQUETI, 2010).

\subsection{Osteoartrite}

A osteoartrite (OA) é uma doença crônica degenerativa que afeta a cartilagem articular, o remodelamento do osso subcondral, membrana sinovial e dos tecidos periarticulares (GOH et al., 2016; ESPINOSA et al., 2016).

A OA é considerada uma das principais causas de redução de qualidade de vida na população, e sua prevalência aumenta rapidamente com a idade (KIADALIRI et al., 2016; PREECE et al., 2016). É estimado em mulheres (18\%) e em homens (10\%) acima de 60 anos de idade possuem OA sintomática e que 50\% das pessoas com mais de 65 anos já apresentam evidencia radiológica da OA (ARDEN e NEVITT, 2006).

A OA geralmente é caracterizada por redução na espessura da cartilagem e alterações no osso subcondral o que danifica toda a cartilagem, incluindo os tecidos sinoviais. Nos estágios iniciais da OA, a sobrecarga mecânica promove um desequilíbrio entre a formação óssea subcondral e a reabsorção, bem como a fabricação da cartilagem e sua degradação. Localmente, os osteoblastos do osso subcondral expressam citocinas e fatores de crescimento tais como IL-1, IL-6, TNFa ou IGF-1, que aumentam a atividade dos osteoclastos conduzindo a um aumento da reabsorção óssea. Eles também induzem uma produção de proteases por condrócitos, tais como MMPs e ADAMTSs. A deterioração da relação OPG/RANKL também ocorre sob carga mecânica, resultando em efeitos pró-catabólicos adicionais tanto na cartilagem quanto no osso (Figura 3-A) (FUNCK-BRENTANO; COHEN-SOLAL, 2011). 
Figura 3-A. Estágio inicial da osteoartrite

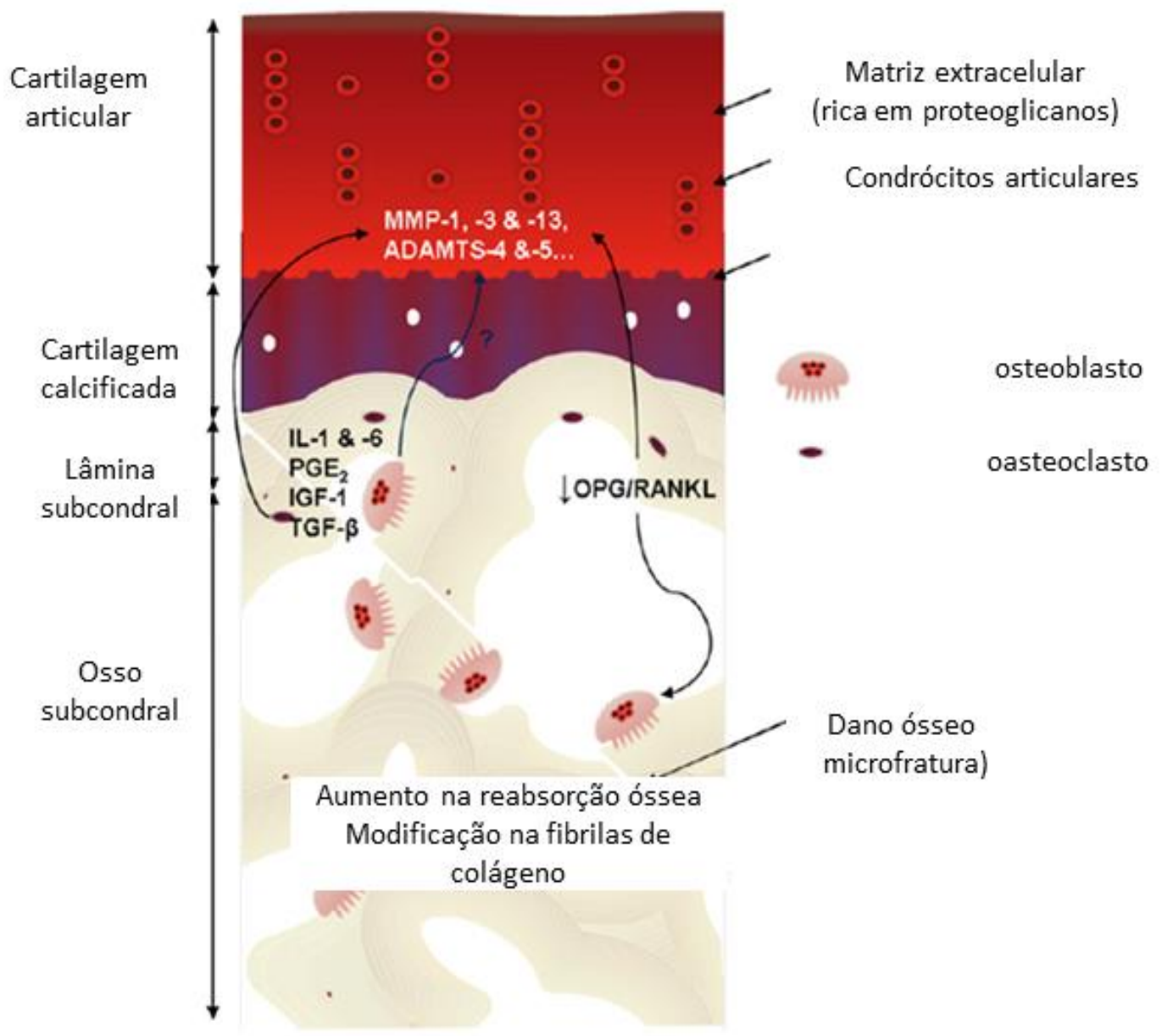

Fonte: FUNCK-BRENTANO; COHEN-SOLAL (2011)

Em estádios tardios da OA, o remodelamento patológico da cartilagem resulta no desgaste da cartilagem articular e na diminuição nos proteoglicanos da matriz, bem como na hipertrofia dos condrócitos. Por outro lado, a cartilagem calcificada abaixo cartilagem articular é espessada, e contém condrócitos apoptóticos e cistos. A neovascularização aparece e o espessamento do osso subcondral está relacionado ao aumento da formação óssea osteoblástica. A via de sinalização Wnt/bcatenina no osso e na cartilagem está envolvida em alterações osteoartríticas. $\mathrm{O}$ efeito de agonistas ou antagonistas Wnt específicos incluindo sFRP-3, DKK-1 \& 2 e SOST nestes tecidos permanece definido (Figura 3-B) (FUNCK-BRENTANO; COHEN-SOLAL, 2011). 
Figura 3-B. Estágio tardio da osteoartrite

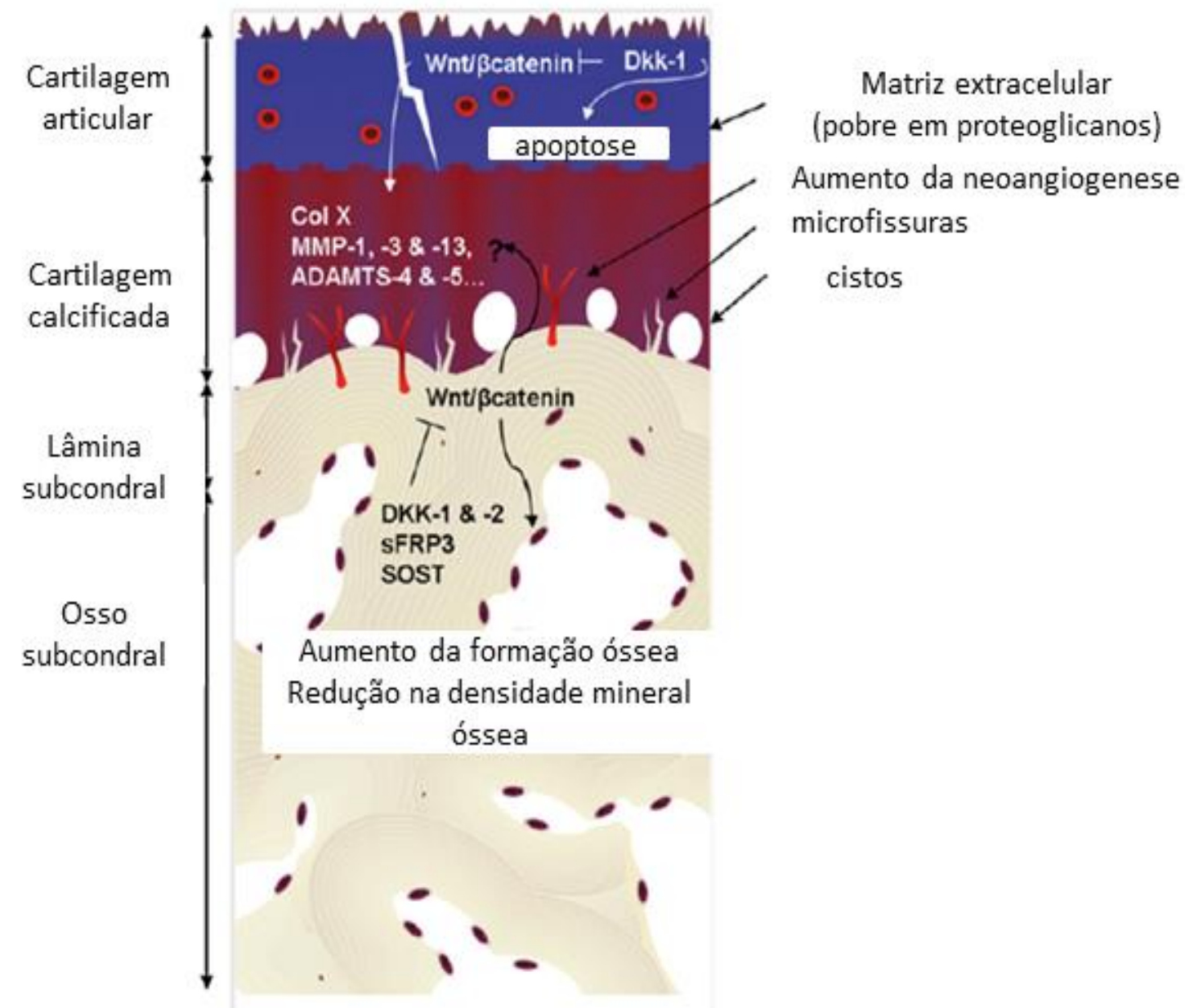

Fonte: FUNCK-BRENTANO; COHEN-SOLAL (2011)

A OA pode causar ainda dor, inflamação, deteriorização das articulações com consequente limitação de movimento principalmente por afetar a articulação do joelho, além da degradação da MEC (CHEN et al., 2016; ARAUJO et al., 2016; TERAUCHI et al., 2016). O joelho e o quadril são as principais articulações afetas pela OA. Os sintomas dessa doença podem causar grande impacto no indivíduo, sobretudo na qualidade de vida e a necessidade de serviços de saúde que consequentemente aumentam direta ou indiretamente os custos na saúde pública (KRAUSS et al., 2016). 
A OA do joelho inicialmente pode ser assimétrica e unilateral, mas com a evolução da doença ela pode passar a afetar bilateralmente (até 80\% dos pacientes desenvolvem em ambas as articulações) independentemente de quaisquer lesões anteriores (METCALFE et al., 2012).

A relação de imagem radiológica e dor estão bem relacionadas e estudadas (KELLGREN, 1961; NEOGI et al., 2009; METCALFE et al., 2012). Quanto maior os sinais radiológicos, ou seja, quanto mais severa for a OA maior a intensidade e frequência da dor e consequentemente redução da função física (METCALFE et al., 2012). A dor na OA não só contribui para limitações funcionais como também é a principal causa de deficiência da mobilidade em idosos (NEOGI et al., 2009).

O tratamento conservador por vezes envolve atividade física, controle da obesidade e exercícios terapêuticos. Esses exercícios podem aumentar a força muscular, estabilizar as articulações e reduzir a perda de cartilagem no joelho (CHANG et al., 2016). Embora a OA não tenha cura, o tratamento individualizado pode melhorar os sintomas, como redução de dor, melhora da capacidade funcional e mobilidade articular através de terapias farmacológicas e não farmacológicas (AMERICAN COLLEGE OF RHEUMATOLOGY SUBCOMMITTEE ON OSTEOARTHRITIS GUIDELINES, 2000). Os efeitos dos programas de exercícios físicos são semelhantes aos analgésicos e antiinflamatórios, sendo o exercício mais vantajoso por não apresentar efeitos colaterais que geralmente essas medicações podem desencadear (KRAUSS et al., 2016; RODDY et al., 2005).

\subsection{Osteoartrite e treinamento resistido}

A estabilidade dinâmica do joelho está relacionada à ação passiva por ligamentos e ativa por atividade neuromuscular. Entre os contribuintes para essa estabilização está o ligamento cruzado anterior (LCA), estrutura que ajuda na rotação e anteriorização da tíbia em relação ao fêmur prevenindo lesões (KIAPOUR e MURRAY, 2014; MURRAY e MACNICOL, 2004). A ruptura do LCA (Figura 4) resulta em danos dos meniscos, cartilagem e outros ligamentos, além

de levar à OA precoce. Nesses casos a OA é originada pela modificação mecânica das articulações, podendo assim causar alterações anatômicas, estruturais e perda da sua função (KOUROUPIS et al., 2016). 
Figura 4. Vista anterior do joelho. Ligamento cruzado anterior.

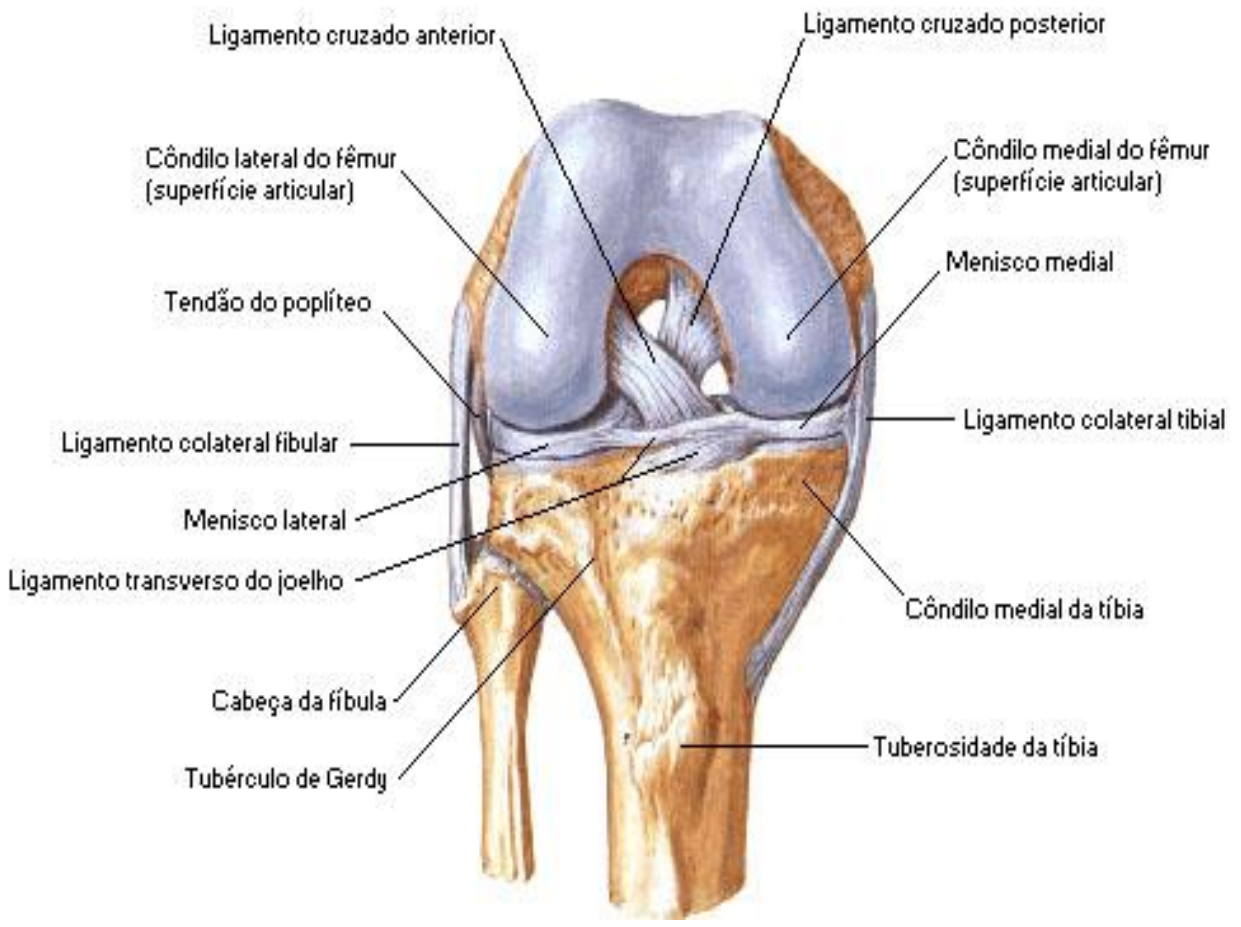

Fonte: NETTER (2015)

O exercício tem sido utilizado tanto na prevenção como no tratamento para melhoria do quadro clínico da $\mathrm{OA}$, principalmente para alivio da dor e melhora da função física (WAINWRIGHT; IMMINS; MIDDLETON, 2016). Uma variedade de fatores fisiológicos como aumento da força muscular, propriocepção e liberação de citocinas tem efeitos positivos quando pacientes com OA realizam exercícios (RUNHAAR et al., 2015).

$\mathrm{O}$ exercício exerce efeito protetor na estrutura e morfologia do tendão e induz ao aumento dos proteoglicanos (FRIZZIERO et al., 2011). Adaptações e modulação morfológica foram encontradas após treinamento resistido como maior deposição de colágeno, elevação de síntese proteica e remodelamento. Essas alterações ocorrem tanto no tendão como no tecido muscular, podendo ser explicado pelo aumento da tensão induzida pelo exercício que visa reforçar a estrutura da junção miotendínea (CURZI et al., 2015).

Estímulos mecânicos têm respostas diferentes sobre a expressão dos proteoglicanos na região tendínea, a tensão mecânica induz a síntese de decorina e no estímulo de compressão há também produção de outros proteoglicanos, como o agrecan por exemplo. Com o exercício, há 
um aumento do turnover da MEC, isso inclui a maturação do colágeno e o aumento do diâmetro das fibrilas (FRIZZIERO et al., 2011; BALDOCK et al., 2001).

Acredita-se que os exercícios resistidos podem ser benéficos na melhoria dos sintomas e da função na OA, principalmente nas propriedades estruturais e periarticulares dos tecidos moles que geralmente são comprometidos e caracterizados por inchaço no joelho na fase aguda da patologia. Além de contribuir de forma positiva na melhoria da qualidade de vida de paciente com OA (GOH et al., 2016).

O exercício resistido na OA tem sido bastante recomendado, pois proporciona melhora na força muscular garantindo a estabilidade articular, melhora da função física, da marcha e do equilíbrio (HUNTER e ECKSTEIN, 2009; LANGE, VANWANSEELE e SINGH, 2008).

\subsection{O papel das metaloproteinases de matriz na osteoartrite}

A manutenção da integridade da MEC envolve a síntese e degradação dos seus componentes, incluindo colágeno, glicoproteínas, glicosaminoglicanos e proteoglicanos (GONZÁLEZ et al., 2002). A expressão de enzimas proteolíticas é essencial para o remodelamento tecidual (STANNARD e BUCKNELL, 1993).

As MMPs são endopeptidases dependentes de cálcio $\left(\mathrm{Ca}^{++}\right)$ou zinco $\left(\mathrm{Zn}^{++}\right)$que desempenham um importante papel na degradação e remodelamento da MEC (GEORGE e DWIVEDI, 2004; ORTEGA, BEHONICK e WERB, 2004; COLLINS et al., 2005). A família de MMPs compreende pelo menos 23 membros nos seres humanos que são reguladas ao nível da transcrição gênica, ativação enzimática e inibição por inibidores teciduais de MMPs (TIMP). Em

condições normais, as MMPs estão presentes em níveis baixos, geralmente em forma latente, e são ativadas para manter o remodelamento fisiológico do tecido (MOTT e WERB, 2004; JONES et al. 2006; PAGE-McCAW et al., 2007). A degradação do colágeno é iniciada no meio extracelular pelas MMPs, particularmente pela MMP-2 e -9 (KJAER, 2004).

As MMPs são geralmente encontradas em tecidos na isoforma pró MMPs e sua expressão é altamente regulada por fatores de crescimento e citocinas produzidas durante o remodelamento tecidual. $\mathrm{O}$ estiramento mecânico causado pelo exercício físico aumenta a expressão gênica das MMPs, resultando em elevados concentrações de MMP-2 e MMP-9 no meio intersticial no tecido peritendinoso humano (KJAER, 2004). 
Tem sido bem demonstrado que o exercício físico aumenta a síntese de colágeno tipo I no tecido conjuntivo peritendíneo do tendão calcâneo em humanos (KJAER, 2004; KOSKINEN et al., 2004).

A atividade da MMP-2 é encontrada em tecidos sob constante remodelamento, e um aumento desta atividade é geralmente indicativo de degradação da MEC, fator fundamental para permitir o crescimento do tecido. A MMP-2 também é conhecida como gelatinase A, ou colagenase tipo IV de $72 \mathrm{kDa}$, que pode ser transformada em uma isoforma ativa de $62 \mathrm{kDa}$, ela regula a integridade da MEC e a composição do músculo esquelético, exercendo um papel essencial na proliferação e diferenciação das miofibrilas, na regeneração das fibras musculares e na manutenção do tecido conjuntivo. A MMP-2 é expressa em mioblastos, bem como em fibroblastos no tecido muscular normal e tem a sua expressão aumentada sob várias condições patológicas, como inflamação e exercício excessivo (MARQUETI, 2010).

Acredita-se que as MMPs têm papel chave na destruição das articulações na OA. Os níveis dessas metaloproteinases são altíssimos na OA e capazes de degradar muitos outros componentes da MEC. Há significativa correlação da MMP-2 na OA sugerindo que esta em alto nível influencia negativamente o tecido sinovial no qual é bastante afetado por componentes inflamatórios durante a progressão da doença (YOSHIHARA et al., 2000). Os mediadores inflamatórios podem causar aumento das MMPs que degradam a matriz. Esse aumento nas MMP-1, MMP-2 e MMP-9 na OA pode acelerar a patogênese da doença, o que reflete clinicamente em dor severa e rigidez articular (NUMMENMAA et al., 2016; ZENG et al., 2015).

As MMPs também promovem o turnover da MEC de todos os tecidos ricos em colágeno como os tendões, músculos e ligamentos e são responsáveis pelo remodelamento tecidual (RITTY; HERZOG, 2003). As MMPs estão entre algumas enzimas fibrilares capazes de clivar todo o colágeno. Elas incluem colagenase 1, MMP-2, MMP-8, MMP-13 e MMP-14. A clivagem ocorre num único lócus da tripla hélice do colágeno, criando 3/4 e 1/4 de fragmentos podendo ainda ser mais degradados por uma variedade de proteases, incluindo as gelatinases, MMP- $2 \mathrm{e}$ MMP-9. (KONTTINEN et al., 1998; RILEY et al., 2002).

Em condições patológicas em que há desequilíbrio na síntese e degradação da MEC, as MMPs têm papel fundamental na renovação do tecido conjuntivo e no processo de remodelação do tecido (RILEY et al., 2002). As MMPs são sintetizadas como pró-enzimas. O peptídeo de sinal é clivado durante a tradução e as isoformas pró das MMPs são geradas (enzimaticamente 
inativas) denominada zimogênios cuja ativação é importante para a regulação das atividades das MMPs (NAGASE; VISSE; MURPHY, 2006).

As atividades das MMPs são controladas por inibidores específicos (TIMPs) como a a2-macroglobulina e localmente os inibidores teciduais de metalopeptidases. Foram identificados TIMP-1, TIMP-2, TIMP-3 e TIMP-4 e sua função é de impedir a degradação excessiva ou descontrolada da produção das MMPs, além de ser essencial na homeostase da matriz extracelular (SIEMIANOWICZ et al., 2015). A MMP-9é responsável pela mediação para liberação do fator de crescimento endotelial vascular (VEGF) e a ativação do TIMP-1 pode restringir essa mediação, enquanto o TIMP-2 regula a MMP-14 e pode restringir a clivagem e consequentemente ativação da MMP2, além de poder ligar-se a integrina $\alpha 3 \beta 1$ nas superfícies das células endoteliais. Essa ligação controla o VEGF e os fibroblastos mediadores dos fatores de crescimento para proliferação celular (STETLER-STEVENSON, 2008).

As MMP-2 e MMP-9 são gelatinases que podem degradar o colágeno tipo IV e outras moléculas bioativas, elas têm atividade proteolítica e podem ser expressas em várias patologias. Os níveis elevados das MMP-2 e MMP-9 na OA podem acelerar a patogênese da doença, o que remete no fator sintomático da mesma, como rigidez e dor severa nos pacientes (ZENG et al., 2015). A MMP-2 pode atuar como uma cascata na ativação da colagenase, com aumento de sua expressão na OA associada com aumento da colagenólise (JACKSON et al., 2014).

O aumento dos níveis de proteína de MMP-1, MMP-2, e MMP-9 em indivíduos com OA em comparação com pessoas normais, têm consequências biológicas significativas sobre a progressão da doença e implicações importantes no diagnóstico precoce e no tratamento da OA (JACKSON et al., 2014; ZENG et al., 2015).

A hipótese do presente estudo é de que o exercício resistido possa ser capaz de promover um melhor remodelamento tedíneo e ligamentar no processo de degeneração da OA. 


\section{OBJETIVO}

O objetivo do presente estudo foi avaliar a atividade da MMP-2 no tendão do quadríceps e no ligamento patelar após 8 semanas de treinamento resistido em um modelo animal de OA induzido pela ruptura do LCA. 


\section{MATERIAIS E MÉTODOS}

Animais: Foram utilizados 36 ratos machos Wistar (com peso aproximado de $300 \pm 10 \mathrm{~g}$ ) do Biotério Central da Universidade Federal de São Carlos, que permaneceram agrupados em gaiolas plásticas, com livre acesso a água e ração. Os animais foram mantidos no biotério do Departamento de Fisioterapia (UFSCar), com as condições ambientais controladas (luminosidade: ciclo de $12 \mathrm{~h}$ claro/escuro). O experimento foi conduzido de acordo com recomendações éticas internacionais (National Research Council, 1996) e o projeto foi aprovado no Comitê de Ética em Experimentação Animal da Universidade Federal de São Carlos (Parecer CEA/UFSCar ${ }^{\circ}$ 021/2010).

Grupos Experimentais: Os animais foram divididos em 6 grupos com 6 animais em cada grupo: Controle (C), Modelo de osteoartrite (OA), Sham (cirurgia placebo) (S), Exercício (E), Modelo de osteoartrite e Exercício (OAE), Sham e Exercício (SE). Os animais dos grupos OA e OAE foram submetidos à cirurgia de transecção do LCA do joelho esquerdo e os grupos S e SE receberam o mesmo procedimento cirúrgico, entretanto sem a transeç̧ão do ligamento. Os animais ficaram em livre deambulação nas gaiolas por duas semanas após a cirurgia, posteriormente os grupos E, OAE e SE iniciaram o protocolo de exercício resistido, três vezes por semana, durante oito semanas. Os grupos $\mathrm{C}, \mathrm{OA}$ e $\mathrm{S}$ permaneceram livres em deambulação no mesmo período do protocolo de exercício resistido. Ao final do experimento, totalizando 10 semanas, todos os animais foram eutanasiados.

Modelo animal de OA: A cirurgia de transecção do LCA foi realizada com os animais anestesiados (injeção intraperitoneal de solução de xylazina $20 \mathrm{mg} / \mathrm{Kg} /$ peso corporal e ketamina $90 \mathrm{mg} / \mathrm{Kg} /$ peso corporal), seguindo as recomendações éticas internacionais (National Research Council, 1996). A cirurgia foi realizada no joelho esquerdo. Previamente a cirurgia, os joelhos dos animais foram tricotomizados e realizada incisão de aproximadamente $1 \mathrm{~cm}$ na região medial do joelho. Posteriormente a patela foi deslocada medialmente e o joelho flexionado a fim de expor o LCA. Com tesoura oftálmica o LCA foi seccionado. Posteriormente, a patela foi recolocada e os tecidos foram suturados (GALOIS et al., 2004). Um teste de gaveta anterior positivo validou a transecção do LCA. Destaca-se que os animais do grupo S e SE receberam os mesmos procedimentos descritos anteriormente, entretanto o LCA foi mantido integro. 
Protocolo de exercício resistido: Os animais escalaram uma escada vertical $(1,1 \times 0,18 \mathrm{~m}$, degrau de $2 \mathrm{~cm}$, inclinação de $80^{\circ}$ ) com uma carga presa em suas caudas (HORNBERG, FARRAR, 2004). O aparato de carga foi preso a porção proximal da cauda do animal com uma fita-adesiva (Micropore ${ }^{\circledR}$ ) (Figura 5). No topo da escada os animais alcançaram uma gaiola (20 x $20 \times 20 \mathrm{~cm}$ ), como apoio. O protocolo de exercício resistido foi adaptado de Hornberger e Farrar (2004). No primeiro dia do protocolo foi calculada a carga de resistência máxima inicial (RMI) para cada animal. Foi feita uma escalada inicial com $50 \%$ do peso corporal do animal $( \pm 150 \mathrm{~g})$, depois foi adicionado uma carga de $10 \%$ do peso corporal do animal ( $\pm 30 \mathrm{~g})$ até o mesmo interromper a subida. Foi interrompido quando o animal permanecia mais de 30 s parado ou quando escorregava. A RMI foi determinada pela última carga que o animal conseguiu realizar uma escalada completa.

Os animais faziam 10 escaladas por sessão com 30 segundos de intervalo entre cada escalada, 3 sessões por semana em dias alternados por um período total de 8 semanas. A carga do protocolo de exercício resistido foi progressiva, na seguinte evolução: $1^{\mathrm{a}}$ e $2^{\mathrm{a}}$ semana $50 \%$ da RMI, semanas 3 e 4 com $75 \%$ da RMI, $5^{\text {a }}$ e $6^{\text {a }}$ semana $90 \%$ da RMI, 7 e 8 semanas com $100 \%$ da RMI. Dois dias antes de iniciar o protocolo, os animais realizaram um protocolo de familiarização, entretanto sem carga. Não foi realizado qualquer estímulo nocivo para o animal realizar a escalada.

Eutanásia dos animais, retirada e armazenamento dos tendões e ligamentos: Após 48 h do término do período experimental, todos os procedimentos experimentais foram realizados com os animais anestesiados, utilizando-se injeção intraperitonial de solução dexilazina (12 $\mathrm{mg} / \mathrm{Kg} /$ peso corporal) e quetamina (95 mg/Kg/peso corporal). Após, os animais foram posicionados em uma mesa cirúrgica em decúbito dorsal, com as patas presas e mantidas em extensão, para assim efetuar a retirada do tendão e do ligamento patelar. Os tecidos foram congelados em nitrogênio líquido e armazenados em freezer a $-80^{\circ} \mathrm{C}$. 
Figura 5. Protocolo de treinamento resistido. Escada vertical.

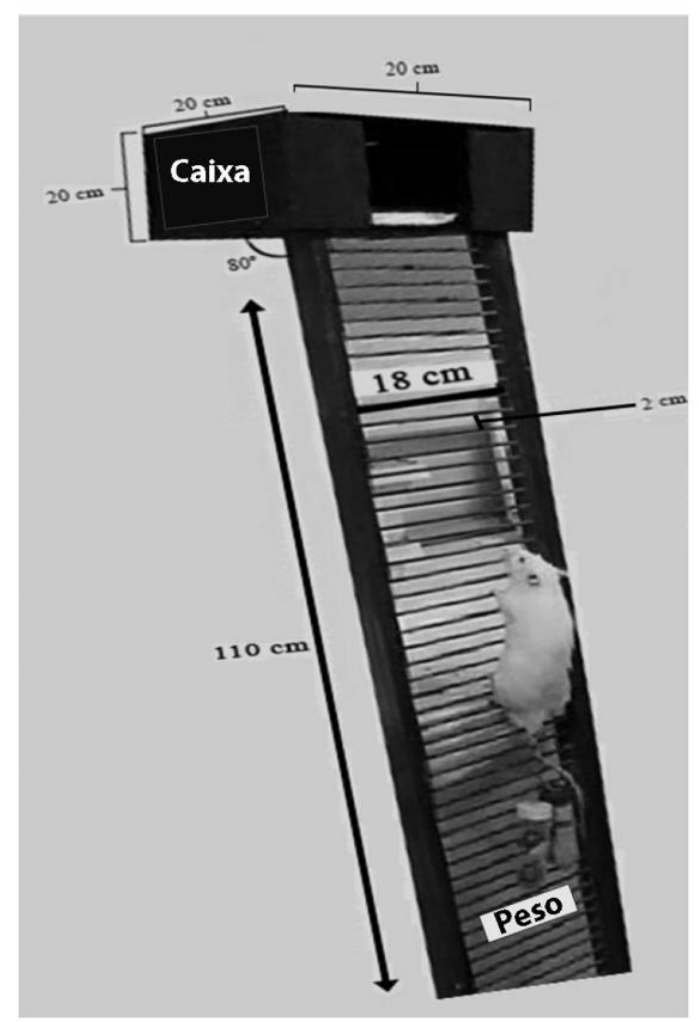

Fonte: CASSILHAS et al. (2012)

Determinação da atividade de MMPs por zimografia: O extrato tecidual das amostras de tendão e de ligamento patelar foi testado para verificar a presença de atividade de proteases através da técnica de zimografia, conforme descrito por Cleutjens (1995). As amostras foram homogeneizadas e incubadas em tampão de extração [10 mM de ácido cacodílico, pH 5,0;0,15 M $\mathrm{NaCl} ; 1 \mu \mathrm{M} \mathrm{ZnCl} ; 20 \mathrm{mM} \mathrm{CaCl}$; 1,5 mM NaN3 e 0,01\% de Triton X-100] (25 mg de tampão para cada mg de tecido) a $4{ }^{\circ} \mathrm{C}$ por um período de 24 horas. Após este tempo o tampão de extração foi coletado por centrifugação $\left(10\right.$ minutos, $4^{\circ} \mathrm{C}$ em $\left.13000 \mathrm{rpm}\right)$. As amostras foram concentradas em $10 \mu \mathrm{g}$ de proteína e $10 \mu 1$ de tampão de amostra sem $\beta$-mercaptoetanol (agente redutor) e foram resolvidas por eletroforese em gel de policriamida contendo dodecil sulfato de sódio (SDS) e gelatina na concentração final de $1 \mathrm{mg} / \mathrm{ml}$. Após a corrida, o gel foi lavado 2 vezes 
durante 30 minutos em solução 2,5\% de Triton X-100 para remoção do SDS. O gel foi incubado no tampão de substrato (Tris-HCI 50mM pH 8,0, CaCl2.5mM; NaN3 0,02\% e ZnCl2 10 mM), a $37^{\circ} \mathrm{C}$, por 20 horas. Após este tempo foi corado com Coomassie Blue Brilliant R-250 (Bio-Rad) e descorado com ácido acético: metanol: água (1:4:5) para visualização das áreas de atividade. Foi utilizado o software "Kodak Digital Science 1D" para fotografar o gel e visualizar a atividade proteolítica das bandas. A análise densitométrica das bandas foi realizada usando o software de imagem GeneTools v3.06software (Syngene, Cambridge, UK).

Análise Estatística: O teste de Kruskal-Wallis H foi utilizado para comparações entre os grupos. Quando apropriadas as comparações de pares foram realizadas utilizando o procedimento de Dunn's com correção Bonferroni para comparações múltiplas. Além disso, para as comparações entre os tecidos (tendão patelar e ligamento patelar), o teste de Mann-Whitney foi também aplicado. $\mathrm{O}$ nível de significância foi de $\mathrm{p} \leq 0,05$. Além disso, todas as análises foram realizadas com o software GraphPadPrism 6.0 (San Diego, Califórnia). 


\section{RESULTADOS}

\subsection{Tendão patelar}

Os resultados mostraram diferenças estatisticamente significativas na MMP-2pró no tendão patelar entre exercício versus grupo OA meanranks (média em cada grupo =6,50 vs. 27,50, respectivamente, $p=0,008)$, exercício versus grupo sham (6,50 vs. 33,50, respectivamente, $\mathrm{p}=0,001)$, osteoartrite versus grupo osteoartrite e exercício (27.50 vs. 6,50, respectivamente, $\mathrm{p}=0,008)$ e osteoartrite exercício versus sham $(6,50$ vs. $33,50, \mathrm{p}=0,001)$ (Gráfico 1A).

Com relação à MMP-2intermediária, foram constatadas diferenças entre exercício versus grupo sham $(15,00$ vs 10,00, respectivamente, $\mathrm{p}=0,035)$, grupo osteoartrite versus osteoartrite e exercício (27.50 vs. 3,50, respectivamente, $\mathrm{p}=0,001)$, osteoartrite e exercício versus grupo controle $(3,50$ vs. 21,50 , respectivamente, $p=0,046)$, osteoartrite e exercício versus grupo sham $(3,50$ vs. 33,50 , respectivamente, $\mathrm{p}=0,001)$, e sham e exercício versus grupo sham (10,00 vs 33,50, respectivamente, $\mathrm{p}=0,001$ ) (Gráfico $1 \mathrm{~B}$ ).

Referente à MMP-2ativa, foi observado as diferenças entre osteoartrite versus osteoartrite e exercício $(32,17$ vs 6,00 , respectivamente, $\mathrm{p}=0,001)$, osteoartrite versus sham e exercício $(32,17$ vs 13,33 , respectivamente, $p=0,029)$ e osteoartrite e exercício versus grupo controle $(6,00$ vs 28,83 , respectivamente, $\mathrm{p}=0,002)$. Verificou-se uma diferença estatisticamente significante entre o grupo exercício e a osteoartrite $(15,00$ versus 32,17 , respectivamente, $p=0,071)$ (Gráfico 1C). 
Gráfico 1. Conteúdo de MMP-2 das isoformas, pró, intermediária e ativa do tendão quadríceps após 8 semanas de exercício resistido.
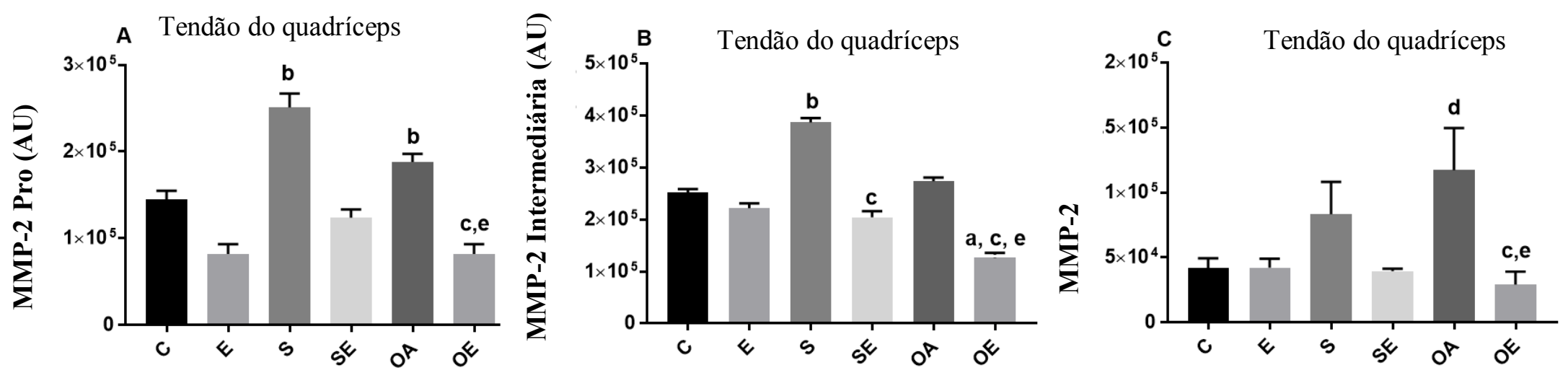

Fonte: Elaboração própria.

Legenda: $\mathrm{AU}=$ unidade arbitrária, $\mathrm{E}=$ exercício, $\mathrm{OA}=$ osteoartrite, $\mathrm{OE}=$ osteoartrite e exercício, $\mathrm{C}=$ controle, $\mathrm{SE}=\mathrm{Sham}$ e exercício, $\mathrm{S}=\mathrm{Sham}$. $\mathrm{a} \neq \mathrm{de} \mathrm{C}, \mathrm{b} \neq$ de $\mathrm{E}, \mathrm{c} \neq$ de SE, $\mathrm{d} \neq$ de $\mathrm{S}, \mathrm{e} \neq$ de $\mathrm{OA}$. A MMP-2 pró, B. MMP-2 intermediária. C. MMP-2 ativa. 


\subsection{Ligamento Patelar}

Com relação ao ligamento patelar, o mesmo mostrou diferença estatisticamente significativa na MMP-2próentre os grupos exercício versus osteoartrite (meanranks = 12,63 vs 39,50 , respectivamente, $\mathrm{p}=0,002$ ), exercício versus grupo sham (meanranks $=12,63$ vs 37,00, $\mathrm{p}$ $=0,009$ ), osteoartrite versus grupo controle (meanranks $=26,25$ vs. 5,77 , respectivamente, $\mathrm{p}=$ 0,047), osteoartrite exercício versus controle (meanranks $=5,77$ vs 12,63 , respectivamente, $\mathrm{p}=$ 0,003), controle versus grupo sham (meanranks $=5,77$ vs 37,00, respectivamente, $\mathrm{p}=0,001$ ) (Gráfico 2A).

Considerando a MMP-2 intermediária, foi observado diferenças entre os grupos, exercício versus osteoartrite (meanranks $=9,62$ vs 33,56, respectivamente, $\mathrm{p}=0,012$ ), exercício versus sham e exercício (meanranks $=9,62$ vs. 38,81, respectivamente, $\mathrm{p}=0,001$ ), exercício versus grupo sham (meanranks $=9,62$ vs 40,63, respectivamente, $\mathrm{p}=0,001$ ), osteoartrite versus grupo controle (meanranks $=33,56$ vs 8,44 , respectivamente, $\mathrm{p}=0,004)$, controle versus grupo sham exercícios (meanranks $=8,44$ vs 37,81, respectivamente, $\mathrm{p}=0,001$ ), e controle versus grupo sham (meanranks $=8,44$ vs 40,63, $\mathrm{p}=0,001)$ (Gráfico 2B).

Com relação à MMP- 2ativa, foi observado apenas as diferenças entre o grupo exercício versus osteoartrite (meanranks $=17,25$ vs. 44,88, respectivamente, $\mathrm{p}=0,001$ ), osteoartrite versus grupo controle (meanranks $=44,88$ vs. 14,44, respectivamente, $\mathrm{p}=0,001$ ) e osteoartrite versus sham e exercício (meanranks $=44,88$ vs 17,00 , respectivamente, $\mathrm{p}=0,001$ ). Verificou-se uma tendência para uma diferença estatisticamente significativa entre os grupos osteoartrite e osteoartrite e exercício (meanranks $=44,88$ vs 24,88, respectivamente, $\mathrm{p}=0,076$ ) (Gráfico 2C). 
Gráfico 2. Conteúdo de MMP-2 das isoformas, pró, intermediária e ativa do ligamento patelar após 8 semanas de exercício resistido.
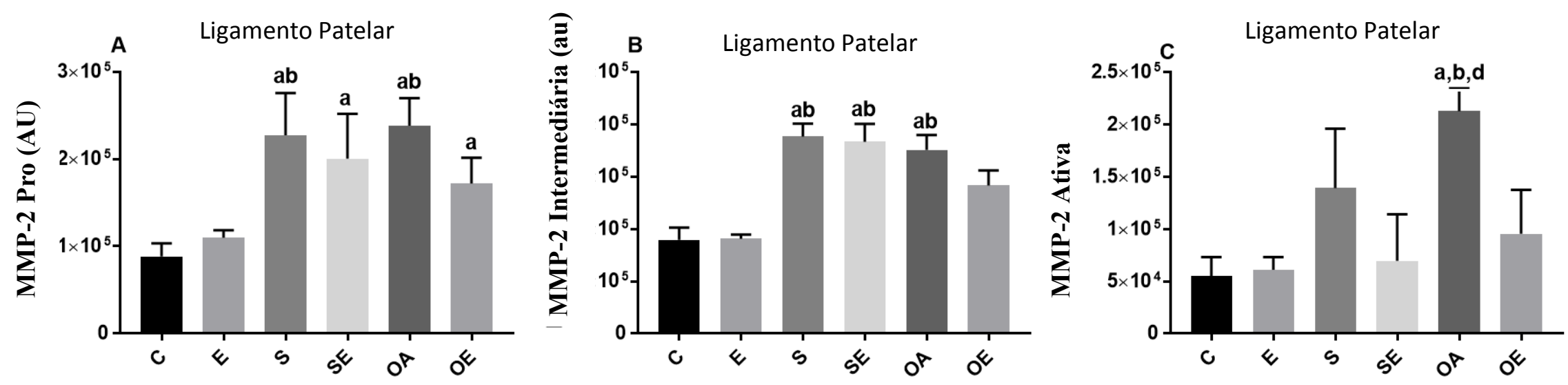

Fonte: Elaboração própria.

Legenda: $\mathrm{AU}=$ unidade arbitrária, $\mathrm{E}=$ exercício, $\mathrm{OA}=$ osteoartrite, $\mathrm{OE}=$ osteoartrite e exercício, $\mathrm{C}=$ controle, $\mathrm{SE}=$ sham e exercício, $\mathrm{S}=\mathrm{Sham}$. $\mathrm{a} \neq \mathrm{de} \mathrm{C}, \mathrm{b} \neq$ de $\mathrm{E}, \mathrm{c} \neq$ de SE, $\mathrm{d} \neq$ de $\mathrm{S}, \mathrm{e} \neq$ de OA. A. MMP-2 pró, B. MMP-2 intermediária. C. MMP-2 ativa. 


\subsection{Tendão do quadríceps versus ligamento patelar}

Com relação à MMP-2 pró, verificou-se uma expressão mais elevada no ligamento patelar entre os grupos exercício $(U=2,00, p=0,003)$, sham $(U=0,00, p=0,001)$, osteoartrite $(U=$ $1,00 \mathrm{p}=0,001)$ e osteoartrite e exercício $(\mathrm{U}=0,00, \mathrm{p}=0,001)$. No entanto, foi identificada uma expressão inferior no ligamento patelar para o grupo controle $(U=0,00, p=0,001)$ (Gráfico 3A).

Para a MMP-2 intermediária, observou-se uma maior expressão no ligamento patelar entre os grupos osteoartrite $(U=0,00, p=0,001)$ e osteoartrite e exercício $(U=0,00, p=0,001)$. Entretanto, observou-se uma expressão menor no ligamento patelar para os grupos controle $(\mathrm{U}=$ $0,00, p=0,001)$ e exercício $(U=0,00, p=0,001)($ Gráfico 3B).

As diferenças entre o tendão patelar versus o ligamento patelar, com relação a MMP-2 ativa, foram verificadas entre os grupos controle $(U=3,00, p=0,005)$, sham e exercício $(U=$ $6,00, \mathrm{p}=0,020)$, osteoartrite $(\mathrm{U}=0,00, \mathrm{p}=0,001)$, e osteoartrite e exercício $(\mathrm{U}=2,00, \mathrm{p}=$ 0,003) com maior expressão no ligamento patelar (Gráfico 3C). 
Gráfico 3. Comparação entre o tendão quadríceps e o ligamento patelar após 8 semanas de treinamento resistido nas 3 isoformas da MMP-2.

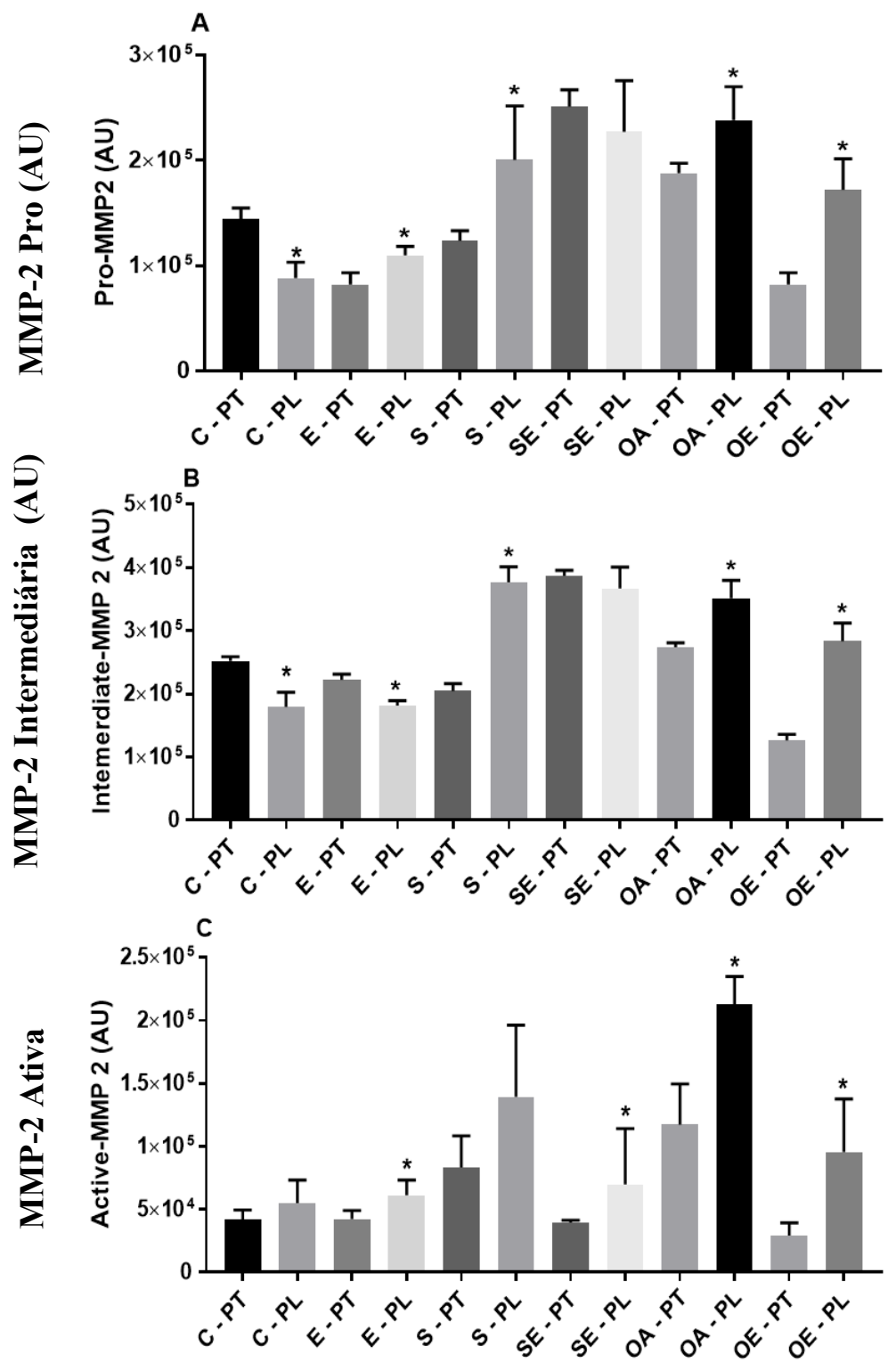

Fonte: Elaboração própria.

Legenda: $\mathrm{AU}=$ unidade arbitrária, $\mathrm{PT}=$ tendão quadríceps, $\mathrm{PL}=$ ligamento patelar, $\mathrm{C}=$ controle, $\mathrm{E}=$ exercício, $\mathrm{S}=$ sham, $\mathrm{SE}=$ sham exercício, $\mathrm{OA}=$ osteoartrite, $\mathrm{OE}=$ osteoartrite com exercício $(\mathrm{p}<0,05)$. 


\section{DISCUSSÃO}

Os achados do presente estudo mostram que o exercício promoveu uma diminuição significativa da MMP-2, principalmente no tendão quadríceps do grupo OE e SE. Além disso, foi observado que o ligamento patelar parece ser mais afetado pela osteoartrite que o tendão do quadríceps, o que pode ser explicado pela demanda tecidual local e aumento de força de contração muscular ser maior no tendão em virtude da sua própria anatomia.

A alta expressão de MMPs está associada a um número de doenças e isso atesta a sua utilidade como biomarcadores importantes para OA e mediador de destruição articular, já que sua expressão é alta na articulação e isso pode predispor à progressão da lesão e à destruição da cartilagem (ROSE; KOOYMAN, 2016). Em lesões que envolvem ruptura de LCA com enxerto de tendão, muitas vezes esses enxertos podem não ser responsivos e acabam sendo substituídos por tecido fibroso cicatricial e esse processo pode levar a instabilidade do joelho e aumentar a chance do indivíduo em desenvolver a OA (WOLFMAN et al., 1997). Embora, esses resultados ainda não estejam claros, sabe-se que o tratamento ou a prevenção de certas doenças que afetam tecidos como tendões e ligamentos são necessários usando estratégias que podem inibir a ativação de alguns membros da família de MMPs (SUN et al., 2008).

De acordo com Assis et al., 2015 o exercício físico (corrida; 16m/min; $50 \mathrm{~min} /$ day) e a terapia a laser de baixa intensidade (LLLT) foram eficazes na prevenção da degeneração da cartilagem e modulação do processo inflamatório induzido pelo $\mathrm{OA}$ em joelho de ratos. $\mathrm{O}$ fortalecimento muscular induzido pelo exercício é uma modalidade terapêutica eficaz, de baixo custo e acessível e que pode desempenhar um papel fundamental no tratamento de OA (AGUIAR et al. 2015). Estudo feito por Martignetti (2001) mostra que a mutação no gene da MMP-2 em humanos pode estar envolvida em doenças como a artrite por afetar o processo de osteogênese levando a reabsorção ou destruição dos ossos.

Com relação a frequência de exercício ideal para a redução do processo inflamatório e consequentemente de MMP-2, estudos anteriores demostraram que exercícios realizados uma única vez (agudo) elevam os níveis das MMPs ao máximo, em um intervalo de tempo relativamente pequeno, atuando como um mediador inflamatório (URSO, 2009; KOSKINEN et al., 2004). Observa-se dessa forma uma resposta adaptativa precoce das MMPs ao exercício agudo, que induzem à uma inflamação aguda, porém, a longo prazo traz como respostas compensatórias a supressão da inflamação além de efeitos anti-inflamatórios. 
No estudo de Malheiro e colaboradores (2009) as seguintes variáveis foram analisadas: espessura, celularidade e vascularização tendínea 1 e 4 dias após exercício de salto e corrida e observaram que na região proximal as MMP-2 pró e ativas foram aumentadas após o salto vertical, mas somente a pró-MMP-2 foi aumentada após a corrida. Em contraste, na região distal, ambos os tipos de exercícios aumentaram a atividade de MMP-2 pró-ativa, principalmente a corrida em esteira, que aumentou a MMP-2 ativa entre 8 e 11 vezes. As MMPs são geralmente encontradas em tecidos na isoforma pró MMPs e sua expressão é altamente regulada por fatores de crescimento e citocinas produzidas durante $\mathrm{o}$ remodelamento tecidual (MARQUETI, 2010).

Em condições normais, as MMPs estão presentes em níveis baixos, geralmente em forma latente, e são ativadas para manter o remodelamento fisiológico do tecido (MOTT e WERB, 2004; JONES et al. 2006; PAGE-McCAW et al., 2007).

Assim, a baixa regulação da ativação MMP-2 parece ser uma resposta positiva para o tendão e ligamento patelar em animais com OA submetido ao programa de exercício resistido. A intervenção mediada pelo treinamento resistido parece sinalizar para a diminuição da expressão de MMP-2, contribuindo para a redução da resposta inflamatória e o processo degenerativo da articulação. Nossos achados sugerem que o exercício resistido é uma ferramenta promissora e eficaz para OA e pode ter um papel fundamental na proteção do tendão quadríceps e ligamento patelar.

As MMPs têm sido envolvidas numa ampla gama de estados patológicos, incluindo a iniciação e metástase do tumor, aterosclerose, OA e artrite reumatoide (ROSE, KOOYMAN, 2016). Além disso, estudo demonstrou que o aumento na MMP-9 (PARKINSON et al., 2010) e a expressão de MMP-13 podem enfraquecer o tendão patelar e predispor à lesão (LAVAGNINO et al., 2006, SUN et al., 2008), tendo efeito drástico no tecido (ROSE, KOOYMAN, 2016). Fatores de crescimento e hormonais estão presentes na MEC dos tecidos do tendão (KJAER et al.,2004) além dos vasodilatores como a prostaglandina que exerce juntamento com o óxido nítrico regulação do fluxo sanguineo durante o exercício (BOUSHEL et al., 2002,2004). Nosso estudo demonstrou que a atividade de MMP-2 é maior no ligamento patelar, indicando um efeito negativo no remodelamento deste tecido, além disso, pode-se observar que quando comparado ao tendão quadríceps aquele é menos responsivo ao treinamento resistido proposto. 


\section{CONCLUSÃO}

Nossos resultados mostraram que o exercício promoveu uma diminuição significativa nas isoformas, pró, intermediária e ativa da MMP-2, principalmente no tendão quadríceps do grupo osteoartrite associado exercício (OE) e sham associado ao exercício (SE). Além disso, foi observado que o ligamento patelar parece ser mais afetado pela osteoartrite que o tendão do quadríceps, o que pode ser explicado pela demanda tecidual local e aumento de força de contração muscular ser maior no tendão em virtude da sua própria anatomia.

Acredita-se que o exercício resistido possa influenciar positivamente os níveis de MMPs e assim promover um melhor remodelamento tendíneo e ligamentar no processo de degeneração da OA e consequentemente gerar uma melhorara no quadro clínico minimizando, até mesmo, o uso de medicamentos.

Algumas limitações precisam ser consideradas nesse estudo, como a falha em não ter analisado a morfologia, a expressão gênica e a biomecânica do tendão do quadríceps e ligamento patelar. Essas análises dariam maiores subsídios para compreender os efeitos da OA nesses tecidos periarticulares, bem como quais os mecanismos alcançados com exercício que conseguem inibir a progressão da doença, principalmente em relação à redução na atividade da MMP-2. 


\section{REFERÊNCIAS}

AGUIAR, Grazielle Cordeiro. et al. Effects of an exercise therapy protocol on inflammatory markers, perception of pain, 444 and physical performance in individuals with knee osteoarthritis. Rheumatology International, v. 35, n. 3, p. 525-531, 2015.

AMERICAN COLLEGE OF RHEUMATOLOGY SUBCOMMITTEE ON OSTEOARTHRITIS GUIDELINES. Recommendations for the medical management of osteoarthritis of the hip and knee. Arthritis \& Rheumatism, v. 43, n. 9, p. 1905-1915, 2000.

ARAUJO, Ivan Luis Andrade. et al. Quality of life and functional independence in patients with osteoarthritis of the knee. Knee Surgery \& Related Research, v. 28, n. 3, p. 219-224, 2016.

ARDEN, Nigel; NEVITT, Michael C. Osteoarthritis: epidemiology. Best Practice \& Research: Clinical Rheumatology, v. 20, n. 1, p. 3-25, 2006.

BALDOCK, Clair. et al. The supramolecular organization of fibrillin-rich microfibrils. The Journal of Cell Biology, v. 152, n. 5, p. 1045-1056, 2001.

BIANCHI, Stefano. et al. Diagnosis of tears of the quadriceps tendon of the knee: value of sonography. AJR - American Journal of Roentgenology, v. 162, n. 5, p. 1137-1140, 1994.

BOUSHEL, Robert. Combine dinhibition of nitric oxide and prostaglandins reduces humans keletal muscle blood flow during exercise. The Journal of Physiology,v. 543, p. 691-698, 2002.

BOUSHEL, Robert. Regulation of blood flow by prostaglandins.Current Vascular Pharmacology, v. 2, n. 2, p. 191-197, 2004.

CASSILHAS, R. C. et al. Resistance exercise improves hippocampus-dependent memory. Brazilian Journal of Medical and Biological Research, v. 45, n. 12, p. 1215-1220, 2012.

CHANG, Wen-Dien. et al. The Effects of Tai Chi Chuan on improving mind-body health for knee osteoarthritis patients: a systematic review and meta-analysis. Hindawi: EvidenceBased Complementary and Alternative Medicine, v. 2016, 2016.

CHEN, Linwei. et al. The inhibition of EZH2 ameliorates osteoarthritis development through the Wnt/ $\beta$-catenin pathway. Scientific Reports, v. 6, 2016.

CLEUTJENS, Jack. P. M. et al. Collagen remodeling after myocardial infarction in the rat heart. American Journal of Pathology, v. 147, n. 2, p. 325-338, 1995.

COLLINS, Kimberly A. et al. De Novo Kinetochore Assembly requires the centromeric histone H3 variant. Molecular Biology of the Cell, v. 16, p. 5649-5660, 2005.

CONNIZZO, Brianne K.; YANNASCOLI, Sarah M.; SOSLOWSKY, Louis J. Structurefunction relationships of postnatal tendon development: a parallel to healing. Matrix Biology: Journal of the International Society for Matrix Biolog, v. 32, n. 2, p. 106-116. 2013. 
CURZI, Davide. et al. Morphological adaptation and protein modulation of myotendinous junction following moderate aerobic training. Histology and Histopathology, v. 30, n. 4, p. 465-472, 2015.

FRIZZIERO, Antonio. et al. Effect of training and sudden detraining on the patellar tendon and its enthesis in rats. BMC Musculoskeletal Disorders, 2011.

FUNCK-BRENTANO, Tomas; COHEN-SOLAL, Martine. Crosstalk between cartilage and bone: when bone cytokines matter. Cytokine \& Growth Factor Reviews, v. 22, p. 91-97, 2011.

GALOIS, Laurent. et al. Dose-response relationship for exercise on severity of experimental osteoarthritis in rats: a pilot study. Osteoarthritis and Cartilage, v. 12, n. 10, p. 779-786, 2004.

GEORGE, Sarah Jane; DWIVEDI, Amrita. MMPs, cadherins, and cell proliferation. Trends in Cardiovascular Medicine, v. 14, n. 3, p. 100-105, 2004.

GOH, Siew-Li. et al. Relative efficacy of different types of exercise for treatment of knee and hip osteoarthritis: protocol for network meta-analysis of randomised controlled trials. Systematic Reviews, v. 5, 2016.

GONZÁLEZ, Arantxa. et al. Regulation of myocardial fibrillar collagen by angiotensin II. A role in hypertensive heart disease? Journal of Molecular and Cellular Cardiology, v. 34, n. 12, p. 1585-1593, 2002.

HORNBERGER, Troy A.; FARRAR, Roger P. Physiological hypertrophy of the FHL muscle following 8 weeks of progressive resistance exercise in the rat. Canadian Journal of Applied Physiology, v. 29, n. 1, p. 16-31, 2004.

HUNTER, David J.; ECKSTEIN, Felix. Exercise and osteoarthritis. Journal of Anatomy, v. 214, n. 2, p 197-207, 2009.

IOZZO, Renato V.; MURDOCH, Alan D. Proteoglycans of the extracellular environment: clues from the gene and protein side offer novel perspectives in molecular diversity and function. FASEB Journal: Official Publication of the Federation of American Societies for Experimental Biology, v. 10, n. 5, p. 598-614, 1996.

JACKSON, Mirian T. et al. Activation of matrix metalloproteinases 2, 9, and 13 by activated protein $\mathrm{C}$ in human osteoarthritic cartilage chondrocytes. Arthritis \& Rheumatology, v. 66, n. 6, p. 1525-1536, 2014.

JONES, Eric J. et al. Stability of a practical measure of recovery from resistance training. Journal of Strength and Conditioning Research, v. 20, n. 4, p. 756-759, 2006.

KELLGREN, J. H. Osteoarthrosis in patients and populations. British Medical Journal, v. 2, 1961. 
KIADALIRI. Aliasghar. A. et al. Association of knee pain and different definitions of knee osteoarthritis with health-related quality of life: a population-based cohort study in southern Sweden. Health and Quality of Life Outcomes, v. 14, 2016.

KIAPOUR, A. M.; MURRAY, M. M. Basic science of anterior cruciate ligament injury and repair. Bone \& Joint Research, v. 3, n. 2, p. 20-31, 2014.

KJAER, Michael. Role of extracellular matrix in adaptation of tendon and skeletal muscle to mechanical loading. Physiological Reviews, v. 84, n. 2, p. 649-698, 2004.

KONTTINEN, YrjöT. et al. New collagenolytic enzymesy/cascade identified at the pannushard tissue junction in rheumatoid arthritis: destruction from above. Matrix Biology: Journal of the International Society for Matrix Biology, v. 17, n. 8-9, p. 585-601, 1998.

KOSKINEN, S. O. A. et al. Physical exercise can influence local levels of matrix metalloproteinases and their inhibitors in tendon-related connective tissue. Journal of Applied Physiology, v. 96, n. 3, p. 861-864, 2004.

KOSTROMINOVA, Tatiana Y.; BROOKS, Susan V. Age-related changes in structure and extracellular matrix protein expression levels in rat tendons. AGE: Official Journal of the American Aging Association, v. 35, n. 6, p. 2203-2214, 2013.

KOUROUPIS, Dimitrios. et al. Generation of stem cell-based bioartificial anterior cruciate ligament (ACL) grafts for effective ACL rupture repair. Stem Cell Research, v. 17, n. 2, p. 448-457, 2016.

KRAUSS, Inga. et al. Effectiveness and efficiency of an 11-week exercise intervention for patients with hip or knee osteoarthritis: a protocol for a controlled study in the context of health services research. BMC Public Health, v. 16, 2016.

LANGE, Angela K.; VANWANSEELE, Benedicte; SINGH, Maria A. Fiatarone. Strength training for treatment of osteoarthritis of the knee: a systematic review. Arthritis and Rheumatism, v. 59, n. 10, p. 1488-1494, 2008.

LAVAGNINO, Michael. et al. Isolated fibrillar damage in tendons stimulates local collagenase mRNA expression and protein synthesis. Journal of Biomechanics, v. 39, n. 13, p. 2355-2362, 2006.

MAGNE, D.; BOUGAULT, C. What understanding tendon cell differentiation can teach us about pathological tendon ossification. Histology and Histopathology, v. 30, n. 8, p. 901910, 2015.

MALHEIRO, Olga Cristina De Mello. et al. Calcaneal Tendon Regions Exhibit Different MMP-2 Activation After Vertical Jumping and Treadmill Running. The Anatomical Record, v. 292, n. 10, p. 1656-1662, 2009.

MARQUETI, Rita de Cássia. Efeitos dos esteroides anabólicos androgênicos sobre a bioquímica, morfologia, biomecânica e expressão gênica de diferentes tendões de ratos submetidos ao exercício de carga. 2010. 207f. Tese (Doutorado em Ciências Fisiológicas) - 
Programa de Pós-graduação em Ciências Fisiológicas, Universidade Federal de São Carlos, São Carlos, 2010.

MARTIGNETTI, John A. Mutation of them atrix metalloproteinase 2 gene (MMP2) causes a multicentrico steolysis and arthritis syndrome. Nature Genetics, v. 28, n. 3, p. 261-265, 2001.

METCALFE, Andrew. et al. Is knee osteoarthritis a symmetrical disease? Analysis of a 12 year prospective cohort study. BMC Musculoskeletal Disorders, v. 13, 2012.

MOTT, Joni D.; WERB, Zena. Regulation of matrix biology by matrix metalloproteinases. Current Opinion in Cell Biology, v. 16, n. 5, p. 558-564, 2004.

MURRAY, Alastair W.; MACNICOL, M. F. 10-16 year results of Leeds-Keio anterior cruciate ligament reconstruction. The Knee, v. 11, n. 1, p. 9-14, 2004.

NAGASE, Hideaki; VISSE, Robert; MURPHY, Gillian. Structure and function of matrix metalloproteinases and TIMPs. Cardiovascular Research, v. 69, n. 3, p. 562-573, 2006.

NEOGI, Tuhina. et al. Association between radiographic features of knee osteoarthritis and pain: results from two cohort studies. BMJ: British Medical Journal, v. 339, n. 7719, p. 498-501, 2009.

NETTER, Frank H. Atlas de Anatomia Humana. 6 ed. Rio de Janeiro: Elsevier, 2015.

NOURISSAT, Geoffroy; BERENBAUM, Francis; DUPREZ, Delphine. Tendon injury: from biology to tendon repair. Nature Reviews Rheumatology, v. 11, n. 4, p. 223-233, 2015.

NUMMENMAA, Elina. et al. Transient receptor potential ankyrin 1 (TRPA1) is functionally expressed in primary human osteoarthritic chondrocytes. Arthritis Research \& Therapy, v. $18,2016$.

ORTEGA, Nathalie; BEHONICK, Danielle J.; WERB, Zena. Matrix remodeling during endochondral ossification. Trends in Cell Biology, v. 14, n. 2, p. 86-93, 2004.

PAGE-McCAW, Andrea. et al. Matrix metalloproteinases and the regulation of tissue remodelling. Nature Reviews: Molecular Cell Biology, v. 8, n. 3, p. 221-233, 2007.

PARKINSON, John. et al. Change in proteoglycan metabolism is a characteristic of human patellar tendinopathy. Arthritis and Rheumatism, v. 62, n. 10, p. 3028-3035, 2010.

Involvement of proteoglycans in tendinopathy. J Musculoskelet Neuronal Interact, v. 11, n. 2, p. 86-93, 2011.

PECORA, Jose Ricardo. et al. Densidade linear do sistema de fibras elásticicas dos ligamentos patelar, cruzado anterior e cruzado posterior. Acta Ortopédica Brasileira, v. 19, n.1, p. 55-62, 2001.

PREECE, Stephen J. et al. Reductions in co-contraction following neuromuscular reeducation in people with knee osteoarthritis. BMC Musculoskeletal Disorders, v. 17, n. 1, 2016. 
REES, J. D. et al. The mechanism for efficacy of eccentric loading in Achilles tendon injury; an in vivo study in humans. Rheumatology, v. 47, n. 10, p. 1493-1497, 2008.

RILEY, Graham P. et al. Matrix metalloproteinase activities and their relationship with collagen remodelling in tendon pathology. Matrix Biology, v. 21, n. 2, p. 185-195, 2002.

RITTY, Timothy M.; HERZOG, Jeremy. Tendon cells produce gelatinases in response to type I collagen attachment. Journal of Orthopaedic Research, v. 21, n. 3, p. 442-450, 2003.

RODDY, E. et al. Evidence-based recommendations for the role of exercise in the management of osteoarthritis of the hip or knee--the MOVE consensus. Rheumatology, v. 44, n. 1, p. 67-73, 2005.

ROSE, Brandon J.; KOOYMAN, David L. A Tale of Two Joints: The role of matrix metalloproteases in cartilage biology. Disease Markers, v. 2016, 2016.

RUNHAAR, J. et al. Identifying potential working mechanisms behind the positive effects of exercise therapy on pain and function in osteoarthritis; a systematic review. Osteoarthritis and Cartilage, v. 23, n. 7, p. 1071-1082, 2015.

SCREEN, Hazel R. C. et al. Tendon functional extracellular matrix. Journal of Orthopaedic Research, v. 33, n. 6, p. 793-799, 2015.

SIEMIANOWICZ, Krzysztof. et al. Effect of elastin-derived peptides on the production of tissue inhibitor of metalloproteinase-1, -2 , and -3 and the ratios in various endothelial cell lines. Experimental and Therapeutic Medicine, v. 9, n. 6, p. 2245-2250, 2015.

STANNARD, James P.; BUCKNELL, Allan L. Rupture of the triceps tendon associated with steroid injections. The American Journal of Sports Medicine, v. 21, n. 3, p. 482-485, 1993.

STETLER-STEVENSON, William G. Tissue inhibitors of metalloproteinases in cell signaling: metalloproteinase-independent biological activities. Science Signaling, v. 1, n. 27, 2008 .

SUN, Hui B. et al. Coordinate regulation of IL-1 $\beta$ and MMP-13 in rat tendons following subrupture fatigue damage. Clinical Orthopaedics and Related Research, v. 466, n. 7, p. 1555-1561, 2008.

TERAUCHI, Koh. et al. The NAD-dependent deacetylase sirtuin-1 regulates the expression of osteogenic transcriptional activator runt-related transcription factor 2 (Runx2) and production of matrix metalloproteinase (MMP)-13 in chondrocytes in osteoarthritis. International Journal of Molecular Sciences, v. 17, n. 7, 2016.

TORNIN, Olger de Souza. Avaliação do tendão quadríceps e ligamento patelar pela ultrassonografia e ressonância magnética em jogadores de futebol assintomáticos. 2012. 86f. Tese (Doutorado em Ciências) - Programa de Pós-graduação em Radiologia, Faculdade de Medicina da Universidade de São Paulo, São Paulo, 2012. Disponível em: $<$ http://bdtd.ibict.br/vufind/Record/USP_77aa9977e6b1d69af7e751692b070704>. Acesso em: 23 ago. 2016. 
URSO, Maria L. et al. Effects of exercise training on the matrix metalloprotease response to acute exercise. European Journal of Applied Physiology, v. 106, n. 5, p. 655-663, 2009.

WAINWRIGHT, Tomas W.; IMMINS, Tikki; MIDDLETON, Robert G. A cycling and education programme for the treatment of hip osteoarthritis: a quality improvement study. International Journal of Orthopaedic and Trauma Nursing, v. 23, p. 14-24, 2016.

WALIGORA, Andrew C.; JOHANSON, Norman A.; HIRSCH, Bruce Elliot. Clinical anatomy of the quadriceps femoris and extensor apparatus of the knee. Clinical Orthopaedics and Related Research, v. 467, n. 12, p. 3297-3306, 2009.

WOLFMAN, Neil M. et al. Ectopic Induction of Tendon and Ligament in Rats by Grow than Differentiation Factors 5, 6, and 7, Members of the TGF-b Gene Family. The Journal of Clinical Investigation, v. 100, n. 2, p. 321-330, 1997.

YOON, J. H.; HALPER, J. Tendon proteoglycans: biochemistry and function. J Musculoskelet Neuronal Interact, v. 5, n. 1, p. 22-34, 2005.

YOSHIHARA, Yasuo. et al. Matrix metalloproteinases and tissue inhibitors of metalloproteinases in synovial fluids from patients with rheumatoid arthritis or osteoarthritis.

Annals of the Rheumatic Diseases, v. 59, n. 6, p. 455-461, 2000.

ZENG, G. Q. et al. High MMP-1, MMP-2, and MMP-9 protein levels in osteoarthritis.

Genetics and Molecular Research - GMR, v. 14, n. 4, p. 14811-1422, 2015. 